\title{
REALISASI MAKSIM PERCAKAPAN DALAM ACARA HITAM PUTIH DI TRANS7
}

\author{
Haswinda Harpriyanti dan Helda Safitri Oktani \\ Program Studi Pendidikan Bahasa dan Sastra Indonesia \\ STKIP PGRI Banjarmasin \\ Email: windabpost@gmail.com
}

\begin{abstract}
Abstrak
Dalam rangka melaksanakan prinsip kerja sama, setiap penutur harus mematuhi empat maksim percakapan. Penelitian ini bertujuan mendeskripsikan tentang realisasi maksim percakapan dalam acara Hitam Putih di Trans7. Masalah penelitian ini berkaitan dengan pelaksanaan, pelanggaran dan faktor penyebab terjadinya pelanggaran maksim percakapan yang terdapat dalam acara Hitam Putih di Trans7.

Penelitian ini merupakan penelitian kualitatif. Metode yang digunakan dalam penelitian ini adalah metode deskriptif. Analisis data penelitian diperoleh bahwa tuturan dalam acara Hitam Putih di Trans 7 telah menggunakan prinsip umum kerja sama dan maksim percakapan Grice serta mematuhi ke empat maksimnya, yakni: Pelaksanaan maksim kuantitas; pelaksanaan maksim kualitas; pelaksanaan maksim relevansi; pelaksanaan maksim pelaksanaan atau cara. Di samping mematuhi prinsip umum tersebut, tuturan dalam acara Hitam Putih di Trans7 terdapat pelanggaran maksim, yakni: pelanggaran maksim kuantitas; pelanggaran maksim kualitas; pelanggaran maksim relevansi; pelanggaran maksim pelaksanaan atau cara.

Hasil penelitian menunjukan bahwa dalam acara Hitam Putih di Trans7 terdapat pelaksanaan dan pelanggaran ke empat maksim percakapan tersebut. Dari analisis pelanggaran maksim percakapan dapat disimpulkan ada beberapa faktor penyebab terjadinya pelanggaran maksim percakapan, yaitu: faktor sosial budaya, faktor humor, faktor keinginan penutur yang ingin meyakinkan dan menginformasikan, serta faktor perluasan atau pengembangan topik pembicaraan dari lawan bicara.
\end{abstract}

Kata kunci: Maksim percakapan

\section{PENDAHULUAN}

Sebagai makhluk sosial, manusia melakukan percakapan untuk membentuk interaksi antarpersonal dan memelihara hubungan sosial. Dalam interaksi kebahasaan ini, bahasa merupakan alat komunikasi yang digunakan untuk menghubungkan situasi, konteks dan maksud berkomunikasi. Dengan berkomunikasi, manusia dapat memenuhi keinginannya sebagai mahluk sosial yang saling berhubungan untuk menyatakan pikiran dan pendapatnya serta bekerja sama.

Ilmu yang mempelajari hakikat dan ciri-ciri bahasa disebut linguistik. Linguistiklah yang mengkaji unsur-unsur bahasa serta hubungan-hubungan unsur itu 
dalam memenuhi fungsinya sebagai alat hubung antar manusia. Pada fungsi ini, bahasa digunakan untuk menyampaikan apa yang ada pada pikiran penutur kepada lawan tutur. Dalam menyampaikan pikiran pasti melibatkan tidak hanya seorang tetapi juga melibatkan beberapa orang. Selain itu, dalam peristiwa tutur si penutur harus bisa saling memahami maksud dari tuturan lawan bicaranya dan keduanya harus mempunyai kerja sama yang baik.

Kerja sama merupakan hal yang harus dilakukan pembicara dan lawan bicara agar proses komunikasi itu berjalan lancar. Grice mengemukakan bahwa dalam rangka melaksanakan prinsip kerja sama itu, setiap penutur harus mematuhi empat maksim percakapan (conversational maxim), yakni maksim kuantitas (maxim of quantity), maksim kualitas (maxim of quality), maksim relevansi (maxim relevance), dan maksim pelaksanaan (maxim of manner) Grice dalam Wijana dan Rohmadi (2009:42).

Prinsip kerja sama ini selain digunakan untuk berkomunikasi juga digunakan dalam hal menyampaikan informasi agar lebih efektif. Penyampaian informasi ini bisa melalui media elektronik yaitu televisi. Televisi merupakan sarana informasi yang menampilkan berbagai program acara, salah satunya yaitu acara Hitam Putih. Hitam Putih merupakan sebuah acara televisi yang sangat menginspirasi bagi penonton. Selain itu, Hitam Putih adalah acara tlak show yang di dalamnya terdapat sebuah komunikasi yang dilakukan penutur dan lawan tutur yang menggambarkan prinsip kerja sama.

Berdasarkan hal di atas, hal yang melatar belakangi pemilihan bahasa dalam acara Hitam Putih adalah karena acara tersebut banyak terdapat fenomena linguistik yang layak untuk dikaji. Kajian tentang realisasi maksim percakapan dianggap penting karena terikat konteks agar antara penutur dan lawan tutur dapat saling memahami dalam berkomunikasi. Komunikasi antara peserta pertuturan tidak akan terlepas dari pertanyaan dan sekaligus permasalahan bagaimana sesungguhnya komunikasi itu dapat terlaksana.

Fokus penelitian ini dengan menggunakan teori implikatur Grice yang mendasarkan diri pada prinsip kerja sama dan maksim percakapan. "Teori itu sengaja dipilih sebab dapat digunakan untuk melukiskan suatu aktivitas kebahasaan yang teratur, terstruktur dan bertujuan jelas” Marcellino, dalam Rani, dkk (2000:232).

Berdasarkan latar belakang di atas, rumusan masalah penelitian ini adalah sebagai berikut.

a) Bagaimanakah pelaksanaan maksim percakapan yang terdapat dalam acara Hitam Putih di Trans7?

b) Bagaimanakah pelanggaran maksim percakapan yang terdapat dalam acara Hitam Putih di Trans7 ?

c) Apa saja faktor penyebab pelanggaran maksim percakapan dalam acara Hitam Putih di Trans7? 


\section{METODE PENELITIAN}

Pendekatan yang digunakan dalam penelitian mengenai realisasi maksim percakapan dalam acara Hitam Putih adalah pendekatan kualitatif.

Hal ini karena Pendekatan kualitatif adalah pendekatan yang diharapkan mampu menghasilkan suatu uraian mendalam tentang ucapan, tulisan, atau perilaku yang diamati dari suatu individu, kelompok, masyarakat dan suatu organisasi tertentu dalam suatu setting konteks tertentu yang dikaji dari sudut pandang yang utuh, komprensif dan holistik Bogdan dan Taylor dalam Basrowi dan Suwandi (2008: 22-23).

Adapun jenis penelitian ini adalah penelitian kualitatif yang menggunakan metode kualitatif deskriptif. Bogdan dan Taylor dalam Basrowi dan Suwandi (2008:21) "Mendefinisikan metode kualitatif sebagai prosedur penelitian yang menghasilkan data deskriptif berupa kata-kata tertulis atau lisan dari orang-orang dan perilaku yang dapat diamati".

Metode yang digunakan dalam penelitian ini adalah metode deskriptif dengan pendekatan kualitatif. Metode deskriptif adalah metode yang berusaha menggambarkan keadaan (objek yang diteliti) secara apa adanya dan kontekstual sebagaimana yang terjadi ketika penelitian ini dilangsungkan.

Adapun sumber data dalam penelitian ini adalah rekaman hasil liputan acara Hitam Putih yang ditayangkan oleh Trans7 setiap hari Senin-Sabtu malam pukul 18.00 WIB. Rekaman program acara Hitam Putih diambil dari edisi bulan FebruariApril 2016. Selanjutnya, ditranskipkan dalam bentuk teks.

\section{HASIL DAN PEMBAHASAN}

\section{A. Realisasi Pelaksanaan Maksim Percakapan dalam Acara Hitam Putih di Trans7}

Berdasarkan Realisasi Maksim Percakapan dalam Acara Hitam Putih di Trans7 dapat ditemukan pelaksanaan keempat maksim percakapan. Keempat jenis maksim percakapan yang dimaksud yaitu maksim kuantitas, kualitas, relevansi dan cara/pelaksanaan. Berikut dialog percakapan dalam acara Hitam Putih.

\section{a) Pelaksanaan Maksim Kuantitas}

Maksim kuantitas menjelaskan bahwa penutur pada umumnya menggunakan bahasa itu tepat, tidak kurang dan tidak lebih, untuk apa yang hendak disampaikan, kepada siapa disampaikan dan untuk tujuan apa. Berikut percakapan yang merupakan tuturan dalam penerapan maksim kuantitas.

[1]

PA D : "Jadi $50 \mathrm{~cm}$ yaa, tadinya berapa yaa?"

NS S : "Awalnya $\mathbf{5 3}$ sudah turun tiga."

Konteks:

Tuturan di atas adalah tuturan antara Pembawa Acara (PA D) Hitam Putih yaitu Deddy Corbuzier dan Narasumber (NS S), yaitu Sendi seorang ibu inspiratif yang mendirikan gerakan Berbagi Kasih Nur Hakim (BKNH) episode Helena, Penulis Buku Tentang Penyandang Kangker. 
Dalam tuturan [1] terlihat bahwa jawaban narasumber telah menerapkan maksim kuantitas. Informasi yang diinginkan [PA D] ialah menanyakan berapa jumlah sebelumnya ukuran lingkar kepala dari anak [NS S] yang bernama Nur Hakim dan jawaban [NS S] sudah memenuhi keinginan itu. Pertanyaan Berapa dijawab dengan jumlah 53. Jawaban [NS S] yang mengatakan Awalnya 53 sudah turun tiga ini bisa dikatakan tepat dan informatif meskipun ada frase Sudah turun tiga itu bermaksud memperjelas jawaban yang disampaikan oleh [NS S].

\section{b) Pelaksanaan Maksim Kualitas}

Maksim kualitas ini berkaitan dengan tanggung jawab penutur. Dalam batasan ini penutur dituntut memberikan informasi yang benar dan mitra tutur dituntut meyakini apa yang disampaikan penutur. Penerapan maksim kualitas dapat dilihat dari tuturan di bawah ini.

[2]

PA D : "Tidak dikirim ke ISU?"

NS V : "Tidak, di ruang biasa, kami sebagai orang tuanya menyetujui dan menandatangani formulir bahwa kami memang tidak mau Anyo itu masuk ISU."

\section{Konteks:}

Tuturan di atas adalah tuturan antara Pembawa Acara (PA D) Hitam Putih yaitu Deddy Corbuzier dan Narasumber (NS V), yaitu Vinta Manulang founder dari yayasan Anyo Indonesia episode Helena, Penulis Buku Tentang Penyandang Kangker.

Tuturan [2] telah menerapkan maksim kualitas, dapat dilihat dari jawaban [NS V] bahwa Ia dan suami memang tidak mengirimkan Anyo ke ISU. Informasi yang diberikan oleh [NS V] mengandung kebenaran dan [NS V] meyakinkan jawabannya dengan menyebutkan bahwa ia dan suami sudah menandatangani formulir. Tuturan [2] telah mematuhi prinsip kualitas yang pertama, yaitu jangan mengatakan sesuatu yang anda yakini bahwa itu tidak benar.

\section{c) Pelaksanaan maksim Relevansi}

Maksim relevansi atau hubungan mengharuskan setiap peserta percakapan memberikan kontribusi yang relevan dengan masalah pembicaraan. Adapun tuturan yang menerapkan maksim hubungan sebagai berikut.

[3]

PA D : : Oke, umur 15 tahun?"

NS H : "Iya."

PA D : : "Berarti masih sekolah donk."

NS H : : "Iya."

PA D : : "Sekolah kelas?"

NS H : "Kelas X, kelas 1 SMA."

PA D : : "X itu 1 SMA yaa. Usia 15 tahun terus nulis buku itu sendiri?"

NS H : : "Iya." 


\section{Konteks:}

Tuturan di atas adalah tuturan antara Pembawa Acara (PA) Hitam Putih yaitu Deddy Corbuzier dan Narasumber (NS H), yaitu Helena seorang anak inspiratif yang menulis buku tentang penyandang kangker episode Helena, Penulis Buku Tentang Penyandang Kangker.

Tuturan di atas merupakan tuturan yang menerapkan maksim hubungan. Tuturan [3] terlihat bahwa jawaban-jawaban dari Helena sesuai dengan pertanyaan. Jawaban yang pertama misalnya relevan dengan pertanyaan [NS D] yang menanyakan tentang Umur 15 tahun?. [NS H] menjawab dengan singkat yaitu Iya. Selanjutnya pertanyaan [PA D] yang menanyakan Sekolah kelas? Sangat relevan dengan jawaban [NS H] yang menjawab Kelas X, kelas 1 SMA. Demikian juga dengan jawaban-jawaban [NS H] selanjutnya yang masing-masing relevan dengan informasi pertanyaanya. Singkatnya, jawaban-jawaban atau informasi yang telah diberikan telah menaati maksim hubungan.

\section{d) Pelaksanaan Maksim Cara}

Maksim cara atau pelaksanaan mengharuskan setiap peserta percakapan berbicara secara langsung, tidak kabur, tidak taksa dan tidak berlebihan. Tuturan yang menerapkan maksim cara sebagai berikut.

[4]

PA C : "Buat Helena ada yang mau disampaikan buat orang-orang yang sedang berjuang melawan kangker?"

NS H : "Pokoknya harus tetap semangat, tetap berjuang dan apapun yang terjadi kalian tidak sendiri."

PA C : "Luar biasa, kalau buat ibu Vinta ada harapan apa untuk rumah Anyo?"

NS V : "Iya, semoga rumah Anyo tetap ada, walaupun hanya satu semoga rumah Anyo bisa menginspirasi seluruh Indonesia jadi akan ada rumah seperti rumah Anyo diberbagai daerah Indonesia. Biarlah ibu-ibu lain yang sama nasibnya dengan saya bisa terinspirasi membuat di daerah mereka masing-masing."

Konteks:

Tuturan di atas adalah tuturan antara Pembawa Acara (PA C) Hitam Putih yaitu Chika Jesika dan Narasumber (NS H \& V), yaitu Helena seorang anak inspiratif penulis buku tentang penyandang kangker dan Vinta Manulang founder dari yayasan Anyo Indonesia episode Helena, Penulis Buku Tentang Penyandang Kangker.

Tuturan di atas menerapkan maksim pelaksanaan karena penutur dan mitra tutur telah memberikan kontribusi yang jelas. Pertanyaan dari [PA C] yang meminta [BT H] untuk menyampaikan sesuatu untuk anak penyandang kangker, dijawab [NS $\mathrm{H}$ ] dengan jawaban singkat dan padat. Begitu juga dengan pertanyaan [PA C] yang ingin tahu apa harapan [NS V] untuk rumah Anyo dan [NS V] mematuhi maksim 
pelaksanaan dengan memberikan tanggapan atas pertanyaan [PA C] secara jelas dan tidak berbelit-belit.

\section{B. Realisasi Pelanggaran Maksim Percakapan dalam Acara Hitam Putih di Trans7}

Berdasarkan Realisasi Maksim Percakapan dalam Acara Hitam Putih di Trans7 dapat ditemukan pelanggaran keempat maksim percakapan. Keempat jenis maksim percakapan yang dimaksud yaitu maksim kuantitas, kualitas, relevansi dan cara/pelaksanaan. Berikut dialog percakapan dalam acara Hitam Putih.

\section{a) Pelanggaran Maksim Kuantitas}

Maksim kuantitas menurut Grice (dalam Yule, 2006:49) adalah "Membuat kontribusi Anda seinformatif mungkin sebagaimana yang diperlukan (untuk tujuan pertukaran percakapan yang ada) dan jangan membuat kontribusi Anda lebih informatif daripada yang diperlukan". Dalam percakapan dalam acara Hitam Putih, ditemukan percakapan pelanggaran maksim kuantitas sebagai berikut.

[1]

PA D : "Dia sakit apa waktu itu?"

NS V : "Dia menyandang reptimo bastoma atau kangker bola mata kasus ke dua terbanyak dan tertinggi di Indonesia."

Konteks:

Tuturan di atas adalah tuturan antara Pembawa Acara (PA D) Hitam Putih yaitu Deddy Corbuzier dan Narasumber (NS V), yaitu Vinta Manulang founder dari yayasan Anyo Indonesia episode Helena, Penulis Buku Tentang Penyandang Kangker.

Tuturan [1] dikatakan melanggar maksim kuantitas karena jawaban dari [NS V] telah melanggar maksim kuantitas yang berbunyi: Jangan membuat kontribusi Anda lebih informatif daripada yang diperlukan. Jawaban [NS V] adalah Dia menyandang reptimo bastoma atau kangker bola mata, setelah jawaban itu diteruskan dengan tambahan keterangan yang sebenarnya dengan jawaban Dia menyandang reptimo bastoma atau kangker bola mata sudah jelas. Pertanyaan [PA D] yang menanyakan Sakit apa hanyalah menginginkan jawaban Penyakitnya yang dideritanya saja. Mungkin maksud [NS V] ingin memperjelas dan menginformasikan, tetapi jawaban tersebut telah melebihi keinginan [PA D].

\section{b) Pelanggaran Maksim Kualitas}

Maksim kualitas mengaharuskan peserta tutur mengusahakan agar pernyataan atau ujaran yang disampaikan dapat dibenarkan sesuai fakta yang ada.

[2]

PA D : "Kalau Nadia punya buku sudah berapa kali cetak?"

NS Ay: "Kalau Nadia punya buku. Emmm, ada baru cetakan pertama ada proses cetakan kedua ada proses cetakan ke tiga."

Konteks: 
Tuturan di atas adalah tuturan antara Pembawa Acara (PA D) Hitam Putih yaitu Deddy Corbuzier dan Narasumber (NS Ay), yaitu Ayah dari Nadia Safiana seorang penulis novel cilik episode Anak dengan Ide di Luar Kepala.

Tuturan [2] dikatakan melanggar maksim kualitas karena informasi yang diberikan [NS Ay] tidak diyakini kebenarannya karena [NS Ay] memberikan jawaban yang melanggar maksim kualitas dengan menjawab Emmm, ada baru cetakan pertama ada proses cetakan kedua ada proses cetakan ketiga. Dari tuturan tersebut terlihat [NS Ay] memberikan informasi yang meragukan dan tidak jelas, selain ia mengatakan baru cetak pertama ternyata memberikan tambahan jawaban dengan mengatakan ada proses cetak kedua, ada proses cetak ketiga jawaban ini tidak sesuai dengan jawaban yang diminta oleh [PA D] yang menanyakan sudah berapa kali cetak. Seharusnya [NS Ay] memberikan jawaban Baru cetak pertama saja sehingga tidak diragukan kebenarannya.

\section{c) Pelanggaran Maksim Relevansi}

Di dalam maksim relevansi atau hubungan dinyatakan bahwa agar terjalin kerja sama yang baik antara penutur dan mitra tutur, masing-masing hendaknya memberikan kontribusi yang relevan tentang sesuatu yang sedang dipertuturkan. Adapun tuturan-tuturan yang menerapkan maksim hubungan sebagai berikut.

[3]

NS H : "1,2 milyar dollar itu harganya hampir 20 triliyun."

PA D : "Om dapat berapa om?"

NS H : "Di kubur di lambo."

Konteks:

Tuturan di atas adalah tuturan antara Pembawa Acara (PA D) Hitam Putih yaitu Deddy Corbuzier dan Narasumber (NS H), yaitu Hotman Paris Sitompul pengacara kondang episode Dibalik Profesi Pengacara.

Tuturan [3] dikatakan melanggar maksim hubungan dikarenakan informasi yang diberikan [NS H] tidak relevan dengan pertanyaan yang diberikan oleh [PA D]. Tuturan [PA D] yang menanyakan Berapa yang seharusnya dijawab dengan Jumlah, namun jawaban [NS H] yang menjawab Di kubur di lambo sama sekali tidak relevan dengan apa yang ditanyakan oleh [PA D].

\section{d) Pelanggaran Maksim Cara}

Maksim pelaksanaan mengharuskan peserta pertuturan bertutur secara langsung, jelas dan tidak kabur.

[4]

PA C : "Ohh iyaa mana ayahnya Nadia. Ayah bener yaa katanya ada buku Nadia yang masuk ke cetakan ke 10?"

NS Ay: "Iyaa tapi itu karya kakaknya, kebetulan kaknya tidak jauh dari Nadia umur 14 tahun dan sekarang cetakan ke 10 atau ke 11 gitu kalau gak salah."

PA D : "Ohh bukan Nadia punya buku?"

NS ay : "Kakaknya." 


\section{Konteks:}

Tuturan di atas adalah tuturan antara Pembawa Acara (PA D \& C) Hitam Putih yaitu Deddy Corbuzier, Chika Jesika dan Narasumber (NS Ay), yaitu Ayah dari Nadia Safiana seorang penulis novel cilik episode Anak dengan Ide di Luar Kepala.

Tuturan [4] merupakan pelanggaran maksim pelaksanaan, dikarenakan [NS Ay] memberikan jawaban yang samar dan tidak jelas yang mengatakan Iya kemudian melanjutkan jawabannya Tapi itu karya kakaknya, kebetulan kaknya tidak jauh dari Nadia umur 14 tahun dan sekarang cetakan ke 10 atau ke 11 gitu kalau gak salah. Sehingga mengharuskan [PA D] mengulang pertanyaannya lagi. [NS Ay] telah melanggar maksim pelaksanaan yang pertama yaitu: Hindari pernyataan yang samar.

\section{Faktor-faktor Penyebab Pelanggaran Maksim Percakapan dalam Acara Hitam Putih di Trans7}

Secara singkat dapat dikatakan bahwa ada 4 faktor yang mempengaruhi pelanggaran maksim percakapan yaitu:

a. Faktor sosial budaya

b. Faktor humor

c. Faktor keinginan penutur yang ingin meyakinkan dan menginformasikan.

d. Faktor perluasan atau pengembangan topik pembicaraan dari lawan bicara.

\section{PENUTUP}

\section{a. Simpulan}

Dari hasil pembahasan yang telah dipaparkan sebelumnya, disimpulkan sebagai berikut.

1. Pelaksanaan maksim percakapan dalam acara Hitam Putih di Trans7 terdiri atas empat maksim yaitu: (a) pelaksanaan maksim kuantitas dapat dilihat dari informasi yang diberikan oleh penutur/mitra tutur yang tidak melebihi pertanyaan; (b) pelaksanaan maksim kualitas dapat dilihat dari jawaban yang diberikan mengandung kebenaran dan dalam penyampaian tidak meragukan; (c) pelaksanaan maksim relevansi dapat dilihat dari jawaban yang diberikan relevan atau berhubungan dengan topik pembicaraan; (d) pelaksanaan maksim pelaksanaan atau cara dapat dilihat dari jawaban yang diberikan oleh penutur/mitra tutur dalam penyampaiannya terlihat runtun, teratur dan sistematis.

2. Pelanggaran maksim percakapan dalam acara Hitam Putih di Trans7 terdiri atas empat maksim yaitu: (a) pelanggaran maksim kuantitas yang terjadi karena adanya keinginan penutur/mitra tutur untuk memperkuat alasan, menambah informasi dan mempertegas jawaban; (b) pelanggaran maksim kualitas yang terjadi karena penutur/ mitra tutur ingin menutupi informasi yang sebenarnya dan informasi yang diberikan meragukan; (c) pelanggaran maksim relevansi yang terjadi karena penutur/mitra tutur berbicara menyimpang dari topik yang ada dan tidak relevan atau tidak berhubungan; 
(d) pelanggaran maksim pelaksanaan atau cara yang terjadi karena penutur/mitra tutur memberikan kontribusi yang samar.

3. Ada beberapa faktor penyebab terjadinya pelanggaran maksim percakapan, yaitu: faktor sosial budaya, faktor humor, faktor keinginan penutur yang ingin meyakinkan dan menginformasikan, serta faktor perluasan atau pengembangan topik pembicaraan dari lawan bicara.

\section{b. Saran}

Sesuai dengan hasil penelitian ini, saran-saran yang dapat dikemukakan sebagai berikut.

1. Diharapkan penelitian ini dapat diaplikasikan oleh dosen dalam pembelajaran, yaitu dipergunakan sebagai bahan ajar pada pembelajaran pragmatik terutama tentang maksim percakapan, sehingga mahasiswa lebih memahami dan mengerti mengenai maksim percakapan dan penerapannya dalam kehidupan.

2. Hendaknya hasil penelitian ini dapat dijadikan acuan bagi peneliti lain dalam melaksanakan penelitian lanjut dengan memfokuskan variabel lain yang masih berkaitan dengan prinsip kerja sama.

\section{Daftar Rujukan}

Basrowi dan Suwandi. 2008. Memahami Penelitian Kualitatif. Jakarta: Rineka Cipta.

Djawad, A.A. 2011. "Implementasi Maksim Percakapan dalam Wacana Kelas di MI Al-Muhajirin Kecamatan Banjarmasin Timur". Laporan Penelitian pada STKIP PGRI Banjarmasin.

Jumadi. 2013. Wacana, Kekuasaan \& Pengajaran Bahasa. Yogyakarta: Pustaka Pelajar.

Moleong, L.J. 1998. Metodologi Penelitian kualitatif. Bandung: PT remaja Rosdakarya.

Rahardi, K. 2005. Pragmatik (Kesantunan Imperatif Bahasa Jakarta: Erlangga.

Indonesia). . 2009. Sosiopragmatik. Jakarta: Erlangga.

Rani, A. A, Bustanul \& Martutik. 2000. Analisis Wacana: Sebuah Kajian Bahasa dalam Pemakaian. Jakarta: Bayumedia

Rohmadi, Muhammad. 2010. Pragmatik (Teori dan Analisis). Surakarta: Yuma Pustaka. 
Sugiono. 2014. Memahami Penelitian Kualitatif. Bandung: Alfabeta.

Wijana, I D.P. dan Rohmadi, M. 2009. Analisis Wacana Pragmatik (Kajian Teori dan Analisis). Surakarta: Yuma Pustaka.

Yule, G. 2006. Pragmatik (diterjemahkan Jumadi). Banjarmasin: FBS FKIP Universitas lambung Mangkurat. 